\title{
Conflictos territoriales y estrategias empresariales en materia de responsabilidad social empresarial (RSE):
} repensando categorías de análisis

\section{Gustavo Pelegrin}

Licenciado en relaciones internacionales.

Becario CEVE-CONICET. Doctorando en Ciencias Políticas, Universidad Nacional de Rosario (FCPRRII-UNR).

gustavopelegrin@ceve.org.ar.

Laila Fleker

Arquitecta. Becaria CEVE-CONICET. Doctoranda en Arquitectura, Universidad Nacional de Córdoba (FAUD-UNC). lailafleker@ceve.org.ar.

\section{María Florencia Pasquale}

Abogada. Doctora en Derecho y Ciencias Sociales. Becaria posdoctoral CEVE-CONICET.

fpasquale@ceve.org.ar.

Aurelio Ferrero

Arquitecto. Investigador independiente de CEVE-CONICET. aferrero@ceve.org.ar.

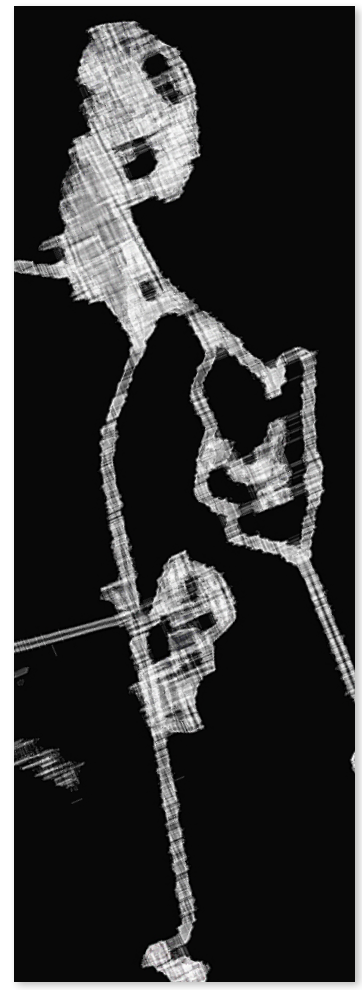




\title{
Resumen
}

En este trabajo se analizarán algunas prácticas de responsabilidad social empresarial (RSE), en pos de visibilizar las múltiples estrategias de inversión desenvueltas en el marco de un programa habitacional desarrollado en Puesto Viejo, provincia de Jujuy, Argentina, durante los años 2013-2016, por una empresa cementera multinacional.

La literatura en materia de RSE, más próxima a los estudios del management, no problematiza la conflictividad social del entorno en que se desarrolla la actividad empresarial en materia ambiental y urbana. Por el contrario, las dimensiones éticas y filantrópicas de su actividad orientan un contenido hacia un público determinado unilateralmente. Por ello, a modo de hipótesis, se sostiene que el reconocimiento del carácter conflictivo de la empresa como actor local en la asignación del territorio es reemplazado por una política dirigida a la gestión de la conflictividad local sin que necesariamente se atenúen los impactos producidos.

\section{Palabras clave}

Responsabilidad social empresarial (RSE); territorio; espacio social.

\begin{abstract}
Land occupation conflicts and corporate strategies in terms of corporate social responsibility (CSR): a reconsideration of categories of analysis.

This paper will analyze some CSR practices aimed at reducing land occupation conflicts between the private sector and the community, in order to reveal the multiple investment strategies developed during a certain historical period. It will begin with the characterization of a housing program developed within the framework of the CSR programs of a multinational cement company.

The literature on CSR, related to management studies, does not recognize the environmental and urban aspects of social conflicts where business activity is carried out. On the contrary, the ethical and philanthropic dimensions of their activity are directed toward a unilaterally chosen public. It is therefore hypothesized that the recognition of the conflictive character of the company as a local actor in the allocation of land uses is replaced by a policy aimed at influencing the management of local conflict without necessarily mitigating the impacts produced by their business activities.
\end{abstract}

Keywords

Corporate social responsibility (CSR); territory; social space. 


\section{Introducción}

Estado, mercado y sociedad civil se interrelacionan y dan lugar a vínculos de cooperación y conflicto socialmente construidos. Las relaciones entre estos actores no siempre son de coordinación, y esas tensiones también tienen su expresión en el territorio. La actividad de las empresas causa impactos que exceden lo económico e inciden en la dinámica laboral, ambiental y social de una localidad, impactos entre los que se cuenta también la organización del territorio. Especialmente en el caso de industrias extractivas, la interacción entre la comunidad local, los gobiernos locales y los provinciales es un tema sensible, ya que requiere la coordinación de las actividades empresariales con las condiciones de vida de la comunidad, a la luz de los objetivos societales que se persiguen. En función de ese reconocimiento por parte de las empresas es que, en las últimas décadas, se ha venido desarrollando el discurso de la Responsabilidad Social Empresaria (RSE) ${ }^{1}$, con la intención de contribuir a una sociedad más justa y sustentable (Instituto Argentino de Responsabilidad Social Empresaria, 2007).

Sin embargo, la literatura en materia de RSE, más próxima a los estudios del management o dirección de empresas, no problematiza la conflictividad social propia del entorno en que se desarrolla la actividad empresarial en materia ambiental y urbana. Por el contrario, las dimensiones éticas y filantrópicas (CARROLL, 1991) de su actividad orientan el contenido de las políticas de RSE hacia un público determinado unilateralmente.

Bajo ese paraguas, la interacción entre Estado, mercado y sociedad civil se adapta a las condiciones sociales locales, las actividades empresarias y las capacidades de los estados locales principalmente. El caso que bajo análisis muestra una experiencia de vinculación entre estos tres sectores en un marco particular de conflictividad social: la de la asignación del territorio, sus usos y funciones para la comunidad, la empresa y el estado local. Esta experiencia se lleva a cabo en una localidad caracterizada por el hacinamiento de hogar - entre otras problemáticas ligadas al territorio-y la implementación de un programa de RSE como producto de la lectura de esas condiciones locales por parte de una empresa cementera multinacional, en la localidad de Puesto Viejo, Jujuy.

A partir de la observación directa en el marco de la ejecución del Proyecto de Investigación Plurianual (PIP CONICET 2013) denominado "Desarrollos socio-técnicos para la gestión integral del hábitat en sectores de bajos ingresos, a partir de recursos facilitados por el sector privado empresarial”, llevado adelante por el CEVE (Unidad Ejecutora de CONICET),
1. Respecto de la terminología empleada, cabe aclarar que en este trabajo se prefiere usar el concepto de Responsabilidad Social Empresaria (RSE) por ser el término que mayor utilización tiene dentro de la literatura específica. A los fines de este trabajo se tomará como sinónimo de Responsabilidad Social Corporativa (RSC). Este último será empleado solo en aquellas oportunidades en que los actores involucrados en el programa analizado así lo denominen. 
2. De acuerdo con el Censo de 2010, el 5,52\% de las viviendas presentaban hacinamiento de hogar. INSTITUTO NACIONAL DE Estadísticas y CENSOS, Censo Nacional de Población, Hogares y Viviendas 2010. se implementó la estrategia de estudio de caso a los fines de comprender las relaciones construidas entre los actores involucrados en el contexto local de referencia, no solo recogiendo sus trayectorias históricas en la localidad, sino también poniendo en diálogo diferentes categorías de análisis que han guiado la implementación de políticas de RSE con otros marcos del pensamiento sociológico propio del constructivismo posestructuralista. A tal fin, se recurrió a la recopilación de fuentes secundarias tales como imágenes satelitales, información estadística relativa a población, hogares y viviendas y la recopilación de fuentes periodísticas y documentos oficiales de la empresa en cuestión en relación con su política de RSE. Adicionalmente se accedió a documentación propia de la vinculación entre AVE (entidad contraparte de CONICET que regula al CEVE) y la empresa referenciada, así como a la documentación técnica de seguimiento de la transferencia y construcción del proyecto habitacional. Asimismo, se realizaron entrevistas semiestructuradas que permitieran dar cuenta de algunos de los significados de los sujetos en torno a la experiencia de articulación bajo estudio. Estas se realizaron durante los días 15 y 16 de septiembre de 2015.

\section{Presentación del caso}

\subsection{Situación habitacional en Puesto Viejo, Jujuy}

La localidad de Puesto Viejo, departamento El Carmen, provincia de Jujuy, en el año 2010 contaba con una población de 1366 personas. Desde el punto de vista habitacional, la problemática que se destaca es la del hacinamiento, principalmente por hogar. En ese entonces, el 39 \% de los hogares de la localidad se encontraba en situación de hacinamiento por hogar, muy por encima de la media nacional ${ }^{2}$. Esta falta de viviendas unifamiliares podría atribuirse a una crónica falta de políticas habitacionales, tanto a nivel local como provincial, situación que se suma a la escasa disponibilidad de suelo urbanizable. Esta situación podría deberse, entre otras razones, al uso agrícola hacia el oeste de la ruta 53, mientras que hacia el este, la casi totalidad de la tierra adyacente al pueblo pertenece a la empresa cementera, sin un uso productivo específico. La crónica falta de políticas habitacionales en la localidad se suma a las condiciones socioeconómicas de las familias de la zona, dependientes en gran medida de la producción de tabaco, entre otros productos agrícolas, y parcialmente del empleo en la cementera.

Sin embargo, en los últimos años se implementaron estrategias para la provisión de soluciones habitacionales multiactorales que se diferencian de las modalidades de producción habitacional tradicionales, que son definidas como la lógica del sector público, la lógica del 
sector privado y la lógica de la necesidad de las familias que producen por fuera de las dos primeras lógicas, al quedar excluidas de ellas (Pírez, 1995). Las nuevas estrategias presentes en la localidad son las siguientes:

- Programa Federal de Autoconstrucción (asistida) de Viviendas, ejecutado por Cáritas Argentina y financiado a través de la Subsecretaría de Desarrollo Urbano y Vivienda de la Nación. Contempló la capacitación en albañilería y el desarrollo de talleres sobre la resolución de conflictos, los roles y las funciones en la familia, la autoestima y la violencia familiar, entre otros ${ }^{3}$.

- Proyecto Pulso Hábitat, dirigido y financiado por la empresa cementera, con la participación de las familias destinatarias, AVE (Asociación de Vivienda Económica), Asociación Bosque Modelo y Fundación EcoAndina.

- Programa provincial “Un lote para cada familia que lo necesite”, implementado en $2011 .^{4}$

Estas iniciativas, que tienen un impacto significativo en la mejora de la situación de hacinamiento local, requirieron la puesta en marcha de marcos particulares de interrelación interactoral. Según un informe realizado por Cáritas Argentina en el año 2015 sobre la situación laboral y habitacional en la localidad de Puesto Viejo, solo el 10 \% de las familias contaba con trabajo formal. Se observó que la mayoría de las personas realizaban "changas" en fincas, efectuando tareas rurales por muy bajos sueldos y sin obra social. Del total relevado, un $47 \%$ de las personas que estaban autoconstruyendo sus hogares eran mujeres, muchas de ellas jefas de hogar. Un alto porcentaje aún residía en condiciones de hacinamiento y precariedad y con acceso limitado al servicio de salud pública (CÁritas Argentina, 2015).

Bajo estas condiciones de dificultad de acceso a la tierra, tanto para uso agrícola como habitacional, en el año 2011 se produjo una serie de tomas de tierras a nivel provincial, y la localidad de Puesto Viejo no quedó exenta. Según se puede constatar en los registros periodísticos, en agosto de 2011 un grupo de vecinos tomó tierras abandonadas pertenecientes a la empresa cementera: "El reclamo no era por bolsones ni vivienda". Una de las vecinas que se encontraba en la toma advertía: "lo que nosotros queremos es estar en el campo, porque lo único que sabemos es producir". En palabras del comisionado municipal de Puesto Viejo: "La gente no quiere donaciones, sino alquilar, arrendar para trabajar" (JujuY AL MOMENTo, 20 de marzo de 2012). En este sentido, un productor de la Asociación de Trabajadores Campesinos de la localidad de Puesto Viejo (JujuY AL Momento, 21 de marzo de 2012) afirmó que 53 hectáreas fueron donadas en el año 1988 y 1989 por la empresa al comisionado municipal de la localidad para
3. En julio de 2017 comenzó la entrega de las viviendas de este programa (GOBIERNO DE JUJUY, 19 de julio de 2017).

4. Sobre esto se puede consultar MINISTERIO DE INFRAESTRUCTURA, SERVICIOS PÚblicos, TIERRA Y VIVIENDA DE JUJUY, SECRETARÍA DE ORDENAMIENTO TERRITORIAL Y VIVIENDA (2016) “Guía para adjudicación de soluciones habitacionales” y (2017) "Sorteo de lotes en Puesto Viejo". 
5. SANTANDREU, A. Y GUDYNAS, E. (1998) proponen clasificar a los conflictos en dos tipos: conflictos manifiestos, entendidos como la expresión concreta de la disputay posición, y los conflictos latentes, en los cuales al menos uno de los actores participantes ha dejado de expresar su oposición en el terreno público, aunque no necesariamente cambiaron sus valoraciones o posiciones. que se convirtiera en un pueblo industrial. En un comunicado de la Corriente Clasista y Combativa (CCC) de marzo de 2013 se solicitaba "mediante un proyecto integral que se devuelvan las 53 hectáreas para producir y vivir" (PARTido ComunisTa Revolucionario, marzo de 2012). Como resulta de las manifestaciones de los diferentes actores que se refirieron al tema de la tierra en la localidad, la escasez para uso habitacional y productivo es un tema de público conocimiento, así como la disponibilidad de tierra improductiva en manos de la cementera.

\subsection{La empresa y su política de RSE en Puesto Viejo}

En el marco del conflicto manifiesto ${ }^{5}$ por el acceso a la tierra en la localidad de Puesto Viejo, la empresa referenciada, a través de su política de RSE, decide poner en marcha un proyecto habitacional. Entre otros actores se involucra a la empresa con las familias destinatarias a través de un desarrollo habitacional. Además se incluye la participación, como premisa en el diseño de la propuesta urbanística y paisajística, la producción de componentes de construcción y la adaptación de las tipologías preseleccionadas. También se promueve una serie de actividades y emprendimientos como estrategia de involucramiento de la comunidad destinataria en el proyecto.

Cuando se le consultó a la trabajadora social a cargo de la coordinación de la parte social del proyecto contratada por la empresa (en adelante TS) acerca del objetivo del proyecto, sostuvo que "viene a contribuir al problema habitacional que tenía la localidad, en el cual la empresa tiene una oportunidad de ceder un espacio que le era propio, con fines sociales y sustentables". La empresa cedió el terreno y solventó la casi totalidad del desarrollo de las treinta viviendas, a la vez que lideró el proceso interactoral a través de la gerencia de RSE. Esta experiencia de articulación ad hoc se caracteriza por la falta de marcos normativos o lineamientos preestablecidos de relacionamiento entre actores de esta naturaleza. La TS del proyecto comentaba al respecto de la respuesta de la empresa en relación con la demanda habitacional en la localidad: "Nosotros arrancamos primero tomando información de encuestas que ya había disponible en estadísticas en la localidad [...] ahí empezamos a identificar gente: qué expectativas tenían, qué necesidades, dónde vivían, cómo era su situación habitacional, si estaban alquilando o si estaban en viviendas prestadas. La mayoría eran viviendas prestadas. O sea, vivían con su familia de origen. [...] Cuando nosotros hicimos la cruza de datos con el municipio, y también el puesto de salud, había un déficit habitacional, yo calculo que de 240 viviendas, más o menos" (Trabajadora Social, entrevista personal, 15 de septiembre de 2015). 
De acuerdo con COMUNIDAD RSE, desde 2013 la empresa trabaja en el proyecto Pulso Hábitat en Puesto Viejo. Este proyecto se basa en la construcción de viviendas "sociales y sostenibles" en el marco de su política de Responsabilidad Social Corporativa y plan de Desarrollo Sostenible 2030. El proyecto tiene por objetivo principal proveer soluciones habitacionales a familias de escasos recursos de la comunidad de la cual forma parte. Para concretarlo, la compañía cedió dos hectáreas de su predio y se definieron los destinatarios directos (treinta familias) a través de una metodología social con criterios comunicados oportunamente. La empresa lideró la construcción de todas las etapas de la obra y, además, las familias destinatarias tuvieron una participación activa durante todo el proceso. En el inicio, en el marco del Panel de Acción Participativa (PAP), luego en la producción de las placas de cerramiento vertical de las viviendas y ventanas. Además recibieron asesoramiento para desarrollar microemprendimientos para generar ingresos que acompañaron la iniciativa (ComUNIDAD RSE, 7 de noviembre de 2016).

Entre los actores ${ }^{6}$ que participaron del desarrollo del proyecto, además de la empresa se encuentran la Asociación de Vivienda Económica (AVE), que asesoró y transfirió la tecnología constructiva para las viviendas desarrolladas en CEVE, su centro de investigación, y acompañó también el proceso del PAP y la estructura general del proyecto; la Asociación Bosque Modelo Jujuy, que aportó el diagnóstico de especies forestales nativas del predio y sugerencias de conservación; la Fundación Eco-Andina, que asistió técnicamente la construcción desde lo bioclimático, tanto de la urbanización del barrio como de las soluciones técnicas; el Ministerio de Vivienda y Ordenamiento Territorial de Jujuy, que contribuyó en la planificación y ejecución de las obras de infraestructura de los servicios básicos; una empresa constructora que fue la encargada de realizar el montaje y terminación de las viviendas y sus servicios; la Comisión Municipal de Puesto Viejo, que formó parte del Consejo Local para la toma de decisiones de manera conjunta en el proceso del proyecto y, finalmente, la comunidad destinataria en las diferentes instancias del proceso. El proyecto comenzó en 2012, desarrolló el prototipo y planificación en 2013 y ejecutó la obra entre 2014 y 2015.

En relación con la presentación del proyecto ante la comunidad local, la TS relataba que "[...] iba a ser un sistema autoconstruido, que iba a ser un sistema participativo, también iban a tener que pagar las viviendas, un porcentaje de lo que salía, la mano de obra ahí también iba incluida. Entonces de ahí tuvimos ese interés de 166 familias, de las cuales,
6. La TS utiliza la terminología "socios estratégicos”. Desde su concepción, la articulación interactoral es definida en términos de asociaciones estratégicas que "aportan valor y otra visión más integrada, más sustentable del proyecto". En el marco del discurso de la RSE, se refiere a estos socios estratégicos dando una idea de horizontalidad, cuando en realidad se trata de asesores contratados para el proyecto bajo los términos de una relación comercial. 
avanzando en el proceso, quedaron 134 familias inscriptas que siguieron por lo menos por

Imagen 1.

Puesto viejo, Jujuy, según usos del suelo.

Fuente: elaboración propia a partir de imagen satelital Google dos años en el proceso, interesadas, que iban a todas las reuniones”. En relación con la participación de las familias en el desarrollo del proyecto, la TS exponía que "armamos lo que fue el PAP, que era el panel de acción participativa. Estos grupos armados de veinte personas cada uno eran seis grupos y con un referente y dos promotores. Teníamos reuniones, a veces semanales o cada quince días con ellos. Reuniones informativas, de consultas, de capacitación, de todo tipo” (TS).

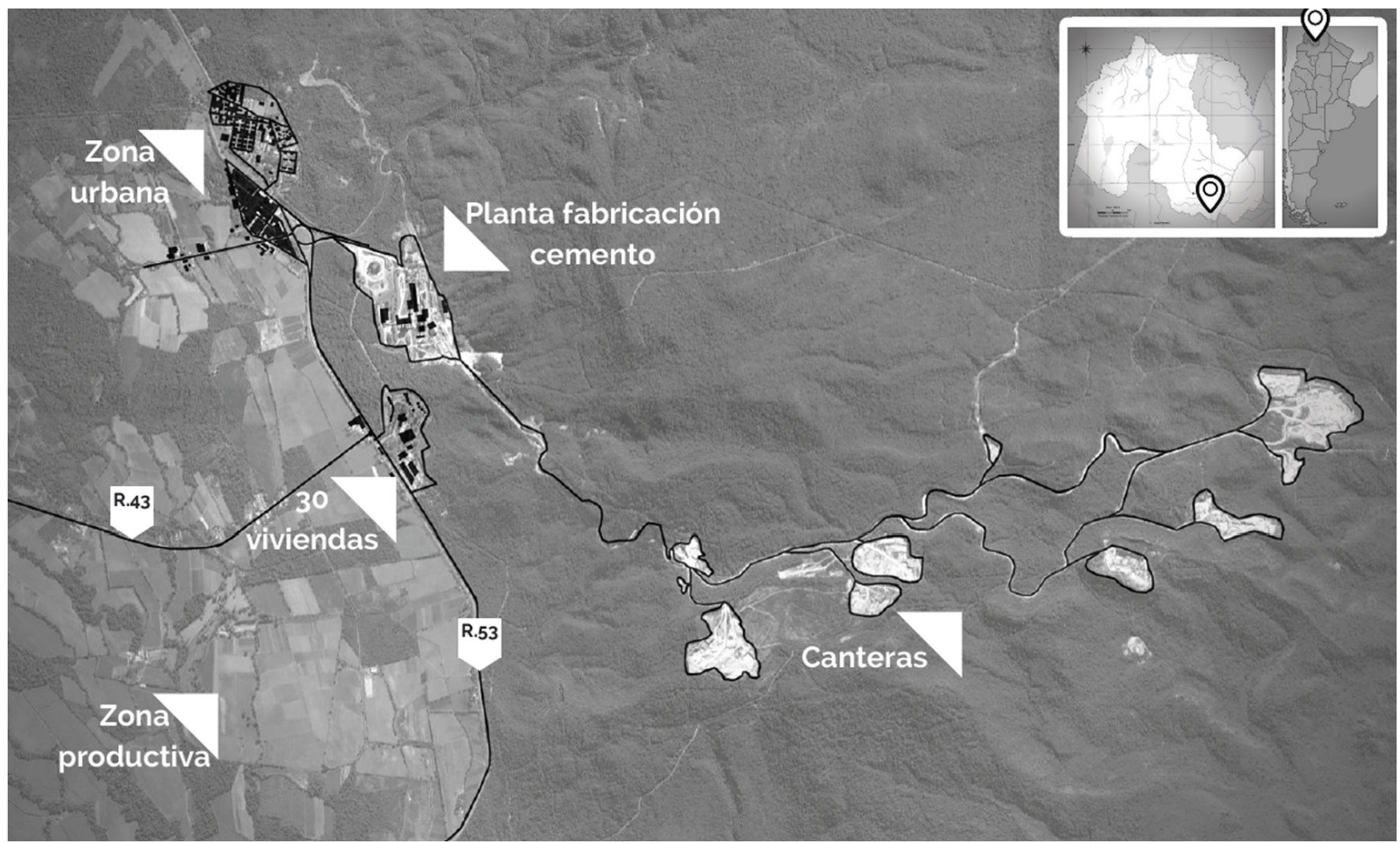


Sobre la titularidad de la propiedad y del terreno: "Primero se traspasa a la Fundación Pulso Hábitat, y de ahí el que va pagando, con su convenio de adhesión, se cancela y se le saca la titularidad. Se le gestiona. Es de ellos. Lo único que va a quedar, digamos, en manos del Estado es la administración de los espacios públicos. O sea, [la empresa] no quiere saber nada después. Ni mantenimiento ni nada. O sea, ya es un barrio en la comunidad" (TS).

\section{Aproximación conceptual}

Si bien el objetivo del presente trabajo no es realizar una exposición acabada de la obra de Pierre Bourdieu, resulta menester una referencia a algunos conceptos del autor y sus interrelaciones, que permitirán observar el espacio social de Puesto Viejo en relación con el desarrollo del proyecto habitacional liderado por la empresa cementera multinacional en Argentina.

La perspectiva sociológica constructivista posestructuralista de BouRDIEu parte de establecer una relación entre las estructuras sociales que direccionan la acción de los agentes, a la vez que agrega a este momento objetivista una dimensión subjetiva en la que las determinaciones de la estructura son incorporadas por los agentes. Sin embargo, aquel condicionamiento estructuralista en BouRdIEu no es de un determinismo mecánico, sino que reconoce a los sujetos la capacidad de agencia, es decir, de que los posibilitantes o condicionantes de la estructura sean incorporados, pero a la vez identificados y modificados por los agentes. Esta puerta de salida al determinismo guarda estrecha relación con los intereses que posean los actores para emprender un curso de acción en las circunstancias en las que se perciben.

A pesar de que lo explicado ut supra parece una obviedad, en el análisis del presente caso esta disquisición entraña la intención de invitar al lector a poner en cuestión los hechos, o mejor dicho, la manera en que los hechos se presentan en la localidad, y abrir la interpretación a múltiples lecturas acerca de espacios sociales como el de referencia. El recurso a un espacio social tiene que ver con una forma de graficar, agrupar y diferenciar a aquellos actores que reúnen ciertas características en un marco determinado, por lo que resulta análogo a un espacio geográfico (GuTierRez y MANSILLA, 2015). Sin embargo, al igual que la categoría "clase social", para Bourdieu ese espacio social "en el papel" (BouRdieu, 1988: 130) es una construcción a la que el observador recurre para representar la proximidad o la distancia entre los diferentes actores presentes en función de un agrupamiento de las propiedades que los hacen pertenecer a diferentes grupos y les otorgan una suerte de identidad
7. "Señalemos que como espacio virtual, la noción de espacio social no se confunde con la de espacio geográfico: define proximidades y distancias sociales, y por ello es diferente al espacio físico $y$ su construcción no supone una dimensión territorial” BOURDIEU en GUTIÉRREZ Y MANSILLA (2015). 
compartida o, por lo menos, agrupada. Por ello, toda vez que se hace referencia al espacio social de la localidad de Puesto Viejo se tratará no solo de un lugar geográfico donde se dan las relaciones que se observan en el presente estudio, sino que resulta útil también para referirse a las posiciones que ocupan los actores en torno a la problemática por la asignación de los usos del suelo y la función social de la propiedad privada.

Estos espacios sociales en los que los agentes se encuentran son analizados por BouRDIEU a partir de la extensión de la lógica económica para el abordaje de los diferentes campos sociales que en ellos coexisten. Estos campos son estructuras dinámicas que dan cuenta de un desarrollo histórico y de la presencia de determinados actores, dotados de determinados capitales, que en función de los intereses que persiguen implementan estrategias de inversión para conservar o aumentar el capital que estructura los intercambios en el interior de ese campo. Por ello, el análisis de un campo informa también sobre las posiciones que ocupan los diferentes actores en relación con la disponibilidad de capital propio, la cantidad global del capital específico de ese campo y la forma en que este se encuentra distribuido en un momento dado.

En función de los diferentes capitales en juego, Bourdieu distingue uno económico, uno de orden simbólico, uno social, entre otros tipos genéricos. A los fines de circunscribir un campo en los términos del autor, es necesario dar cuenta del tipo de capital que da especificidad a ese campo y en torno al cual se ponen en marcha las estrategias de producción y reproducción de este. Dar cuenta de capitales específicos diferenciables permite aislar unos campos de otros, los que se desarrollan siguiendo lógicas de intercambio que le son propias de cada campo. Sin perjuicio de ello, la autonomía de los campos no implica un aislamiento sino analítico, dado que en la complejidad de la totalidad social, los diferentes campos frecuentemente se interrelacionan, retroalimentan y llevan a formas complejas de reconversión de un tipo de capital en otro u otros que contribuyen a conservar o incrementar el capital en otros campos.

Una vez comprendidas las características del espacio social de referencia, los actores ponen en marcha diversas estrategias de reproducción social que Bourdieu define como "conjunto de prácticas fenomenalmente muy diferentes, por medio de las cuales los individuos y las familias tienden, de manera consciente o inconsciente, a conservar o a aumentar su patrimonio, y correlativamente a mantener o mejorar su posición en la estructura de las relaciones de clase” (Bourdieu, 1988: 122). 
Las estrategias que resultan de mayor interés en el presente trabajo son las de inversión económica y las de inversión simbólica. Las primeras se definen como aquellas que "tienden a la perpetuación o el aumento del capital bajo sus diferentes formas", mientras que las simbólicas son aquellas que "apuntan a conservar y a aumentar el capital de reconocimiento (en los diferentes sentidos) propiciando la reproducción de los esquemas de percepción y de apropiación más favorables a sus propiedades y produciendo las acciones susceptibles de apreciación positiva según esas categorías” (Bourdieu, 2014: 37). De esta manera, al producir y reproducir la vida social, agentes y estructuras producen y reproducen también las condiciones que generan y sostienen las situaciones de desigualdad y dominación que las sustentan (GuTIÉRREz, 2011).

\section{Análisis de caso}

El objetivo general de este apartado es visibilizar el funcionamiento de categorías en materia de RSE, los discursos que estructuran y su aplicación a espacios sociales más amplios, como el caso de Puesto Viejo analizado en este trabajo. Para ello se recuperará parte de los aportes introducidos en la literatura de RSE, en especial la denominada "teoría de los Stakeholders" desarrollada por R. E. FreEMAn y la denominada “teoría de la pirámide” desarrollada por A. CARROLL. El análisis se centrará en dos dimensiones. La primera presentará rasgos específicos de las teorías dentro de la literatura en materia de RSE; la segunda buscará colocar directamente en diálogo dichas interpretaciones con la teoría bourdiana, a partir del análisis empírico del caso de Puesto Viejo. Ambas dimensiones se presentarán de modo simultáneo.

\subsection{Grupos de interés}

El término stakeholders (grupos de interés) fue inicialmente acuñado por el Stanford Research Institute (SRI) en 1963. En un memorándum interno se refería a este concepto como "aquellos grupos sin cuyo apoyo la organización dejaría de existir". La lista que acompañaba esa definición incluía a los accionistas, empleados, clientes, proveedores, prestamistas y a la sociedad en general. El concepto surgió como una ampliación del concepto de stockholders (accionistas), para dar cuenta de la existencia de otros grupos, además de los accionistas, con quienes las organizaciones debían ser responsables.

El problema para FREEMAN Y REED (1983) era que la sustitución del término stockholders por el de stakeholders necesitaba una explicación de orden conceptual que hasta el momento no había sido dada. Uno de los problemas, de orden conceptual, radicaba en que la definición 
del SRI resultaba demasiado amplia para poder identificar a los stakeholders externos de relevancia organizacional. Por ejemplo, el caso de los consumidores o la sociedad, donde se perdía de vista la segmentación en su interior y los intereses específicos de los grupos que los componían. Para ello FreEman adoptó dos nuevas definiciones, una en un sentido amplio y otra en uno más acotado. En sentido amplio definió a los stakeholders como "aquellos grupos o individuos que pueden afectar o son afectados por el logro de los objetivos empresariales” (FrEEMAN y REED, 1983). En esta definición entrarían los grupos de interés público, grupos de protesta, agencias de gobierno, asociaciones comerciales, competidores, uniones, así como también empleados, segmentos de consumidores, accionistas, entre otros. Desde el punto de vista de las estrategias organizacionales, FrEEMAn sugiere acuñar la definición en sentido amplio. En un sentido más acotado los definió como "aquellos grupos o individuos de quienes depende la organización para su supervivencia” (FREemAn y ReED, 1983). Esta definición contempla a los empleados, segmentos de consumidores, proveedores, agencias de gobierno claves, accionistas, ciertas instituciones financieras, entre otros.

A través del marco de relacionamiento de los grupos de interés, se busca comprender y mejorar la gestión de los intercambios tanto internos como externos entre los stakeholders. En este sentido, GonzÁlez Esteban (2007) sugiere que la teoría de los stakeholders nace con vocación de ser una teoría estratégica de gestión. En las entrevistas realizadas a referentes de la empresa bajo estudio, destaca el uso de la terminología "grupo de interés" como en general la conciencia de la existencia de grupos que pueden afectar o son afectados por los objetivos de la empresa (stakeholders en sentido amplio). Al decir de la TS: "Hicimos reuniones abiertas en distintos sectores, para ver la gente y también recibir esa información, y después elaboramos encuestas y entrevistas que fuimos haciendo a la población, por sectores. Y bueno, también de los públicos de interés que nosotros teníamos conocimiento que tenía algún tipo de problema habitacional, también los convocábamos, les presentábamos la idea del proyecto, y ahí íbamos armando grupos de interés”.

Posteriormente, FREEMAN (2004) presenta una distinción entre varios tipos de stakeholders, según sea su influencia directa o indirecta sobre la empresa. Distingue entre los "primarios" o "definicionales" y los stakeholders "instrumentales". Los primarios son vitales para el crecimiento continuo y sobrevivencia de cualquier empresa, mientras los stakeholders instrumentales están en el entorno amplio de la empresa, y son aquellos que pueden influir a los primarios (activistas, competidores, ambientalistas, medios de comunicación, etc.). 
Nos detenemos en este punto a fin de realizar una interpretación de las categorías presentadas a la luz de un análisis bourdiano. Consideramos que las descripciones en materia de grupos de interés o stakeholders tales como la presentada no dan cuenta del rol central que tiene el actor "comunidad" en tanto agente que condiciona de modo relevante el escenario en materia de RSE. Los diferentes tipos de stakeholders parecen presentarse, bajo esta teoría, en pie de igualdad, o bien dando mayor relevancia a actores internos considerados "definicionales" que a los externos, y llama la atención que tanto la comunidad como activistas/ militantes por el acceso a la tierra productiva sean considerados meramente "instrumentales”. Sin embargo, siguiendo a Bourdieu, se considera que la complejidad de las dinámicas del ámbito específico de la RSE sería la que determina el rol principal o secundario de cada actor. La posición de principal o secundaria en el contexto específico de la RSE no puede interpretarse sin considerar el especial capital alrededor del cual despliegan sus diversas estrategias de inversión (tanto de capital económico como simbólico) dentro de ese marco. "[La empresa] va buscando formas nuevas de sostener esa relación con todos los públicos de interés que tiene [...] Primero era la comunidad acá, en la zona donde tiene influencia la planta, después los empleados también, porque había en algún momento una demanda del tema habitacional y la problemática que veíamos” (TS).

Para algunos de los actores involucrados en el proyecto habitacional, el concepto de RSE se funde con la noción de la responsabilidad que tiene la empresa para realizar viviendas para sus empleados. "Y en realidad yo te diría que no sé si es tan nuevo o reciente esa oleada o moda, o ganas de que la responsabilidad social corporativa los lleve a que una empresa haga casas ¿no? Por qué acá por ejemplo tenemos la mina El Aguilar” [...], que en la década del 60 ya tenía su barrio. Necesariamente esa empresa ya hizo casas para sus empleados. Y ahí era para toda la plantilla completa. Diferenciado sí por sectores. Estaban los jerárquicos por un lado, los que tenían cierto cargo, y los operarios por otro. Pero ya hicieron casi una ciudad con polideportivo, con casino, comedores, con todo. Estamos hablando en la época del 60, 70. Porque yo me acuerdo, tengo gente conocida, abuelos, gente grande que trabajó ahí y cuentan... Cuentan cómo se vivía en esa época, y bueno, ahora es otra, otro reflotado quizás de esos conceptos. Porque ahora es como un boom que se ha dado en las empresas. Acá particularmente en Jujuy, yo lo único que conozco es Holcim y Ledesma”. Jefe de obra del proyecto (JO).

Según el discurso oficial ("la empresa como un vecino más") que se deja entrever a partir de las opiniones de sus trabajadores, la empresa propone igualar a los grupos de interés (stake- 
8. BERT SPECTOR (2008) afirma que la literatura en materia de RSE surge como un medio para alinear los intereses comerciales en defensa del capitalismo de libre mercado en el contexto de la Guerra

Fría, en contra de lo que se consideraba el peligro del comunismo soviético. holders), al menos discursivamente. En este caso, a la comunidad con la empresa, ocultando las desigualdades y los intereses puestos en juego mediante las estrategias de inversión simbólica de esta última. "La empresa fundamentalmente en todo lo que es responsabilidad social corporativa habla mucho de la sostenibilidad, como uno de los principios rectores para la generación de valor y también para sus modos de hacer y producir. Entonces esa sostenibilidad es muy vinculada con el área de responsabilidad social [...] Y después también en relación a cómo se posiciona la empresa en la comunidad, que es un vecino más que va a aportar en una estrategia de desarrollo local” (TS).

\subsection{Dimensiones de la RSE}

Durante los años 1960-19708, la responsabilidad social se pasa a analizar como una dimensión independiente del desempeño económico de los negocios. La separación de la responsabilidad empresaria en dos dimensiones, la social y la propiamente económica, representará el primer esbozo de lo que más tarde ARCHIE CARRoll desarrollará como la "teoría de la pirámide". Al decir del autor, "la responsabilidad social comenzó a estar guiada principalmente por motivaciones externas y sociales que no buscan ningún retorno, antes que por motivaciones centradas exclusivamente en los negocios” (CARRoll y SHABANA, 2010).

Recuperando los conceptos de capital simbólico y autonomía de los campos presentados anteriormente, se podría decir en términos de BouRdiEu que la responsabilidad social como campo específico en disputa no puede dejar de producir algún tipo de retorno, en este caso, específicamente de capital simbólico. No sería posible, dentro de esta interpretación, referirnos a que un intercambio no produce retorno de algún tipo, aunque directamente no "busque" un retorno en el campo económico, tal como refiere la cita anterior. El hecho de que el retorno no pueda cuantificarse en términos económicos no significaría que no exista en una dimensión simbólica ligada, por ejemplo, a la reputación de la empresa en un determinado espacio social.

En referencia a la autonomía de los campos, cabe decirse que si bien cada campo social es susceptible de contar con un específico capital que lo estructura, la autonomía no implica únicamente aislamiento, sino también interrelación, por lo que es posible, por ejemplo, pensar que el capital simbólico retroalimenta al capital económico de la empresa, y viceversa.

Por ejemplo, en el discurso acerca de los negocios inclusivos esgrimido por TS, contrario a las primeras conceptualizaciones de CARROLL, se revela que siempre se espera algún retorno 
(“ahorro” o “excedente”): "Básicamente [el negocio inclusivo] es el valor compartido. Un valor tanto para la empresa como un valor para la sociedad. Está sí o sí orientado hacia poblaciones vulnerables que participan en este proceso. Primero que puede ser como beneficiario o participa en el proceso productivo y que la empresa haga algún tipo de beneficio en distintos conceptos, generándose algún ahorro o algún excedente de ingreso o se beneficie en algo”.

La perspectiva de ARCHIE CARRoll identificó diferentes categorías de la RSE que representan lo que McGuire (1963) había esbozado como las "responsabilidades que se extienden más allá de las responsabilidades legales". Estas, al decir de CARROLL (1991), incluyen el cumplimiento de responsabilidades que pueden separarse en cuatro dimensiones: económica, legal, ética y discrecional. Carroll afirma que "La responsabilidad social de las empresas abarca las expectativas que tiene la sociedad para con las empresas, en un momento determinado, en los campos económico, jurídico, ético y discrecional (posteriormente se denomina responsabilidad filantrópica)" (CARRoLL, 1991). Al decir del autor, las categorías ética y filantrópica se distinguieron de las responsabilidades económicas y jurídicas: en tanto estas últimas eran "necesarias", las responsabilidades éticas eran "esperadas” y las responsabilidades discrecionales/filantrópicas, "deseadas".

El autor teoriza el contenido de las responsabilidades "tradicionales" (económica y legal) de la empresa, frente a las "nuevas" responsabilidades (ética y filantrópica). Colocaremos en lo sucesivo en foco las "nuevas" responsabilidades (ética y filantrópica) de la empresa. Los primeros trabajos de CARRoLL (1991) definieron la Responsabilidad ética como aquella que representa un comportamiento que la sociedad espera de la empresa, pero que no está codificado en ninguna ley. Responsabilidad filantrópica, por otro lado, es aquella que es asumida solo por el deseo de dar solución a los problemas de la sociedad. Es totalmente voluntaria y no está sujeta a ningún tipo de regulación ni mandato de carácter ético.

En desarrollos teóricos más recientes, Carroll y Shabana (2010) explicitan el contenido de las responsabilidades éticas y filantrópicas distinguiendo entre una visión estrecha y una visión amplia en materia de RSE. En la visión estrecha, las iniciativas empresariales se encuentran justificadas cuando redundan en beneficios directos al desempeño económico de la empresa. En la visión amplia, diversas iniciativas se encontrarían justificadas cuando redundan en beneficios tanto directos como indirectos. Desde esta última perspectiva, las estrategias de inversión en materia de responsabilidad social son valoradas siempre como 
9. En pos de profundizar sobre nuevas aproximaciones en este sentido, en materia de RSE resulta de interés revisar el aporte de KURUCZ ET ÁL.

(2008). "oportunidades" y no meramente como "costos". En el mismo sentido, dicha postura considera que las estrategias de responsabilidad social se esfuerzan por comprender la naturaleza compleja e interrelacional que media entre responsabilidad social y desempeño económico-financiero de la empresa.

En este punto del análisis interesa detenerse a fin de destacar la evolución hacia una visión amplia que ha experimentado la teoría en materia de RSE, y su aproximación hacia un análisis bourdiano que otorga especificidad a la dimensión social (que abarca responsabilidad ética y filantrópica en términos de CARROLL), en tanto campo específico en el que se disputa un capital simbólico de reconocimiento que cumple el específico rol de reducir costos y riesgos ${ }^{9}$ para la empresa. Afirmar que la participación en determinadas actividades en materia de RSE reduciría los costos y los riesgos para la empresa parte del supuesto de que las demandas que los stakeholders realizan a la empresa representan amenazas a la reproducción del capital económico así como lo conciben sus accionistas.

Se observa de este modo un desplazamiento de un rol accesorio al capital económico que cumple la RSE bajo la visión estrecha, hacia un rol central en que se disputa un específico capital simbólico. En este último, es central el rol activo que asume la empresa en la gestión de la conflictividad a nivel local. Este desplazamiento puede observarse en las entrevistas realizadas. Específicamente observamos que frente a la pregunta sobre por qué crees que la empresa realiza este proyecto, una de las destinatarias responde que "lo único que quiere es tapar el sol con un dedo":

"Entrevistador: ¿Por qué [crees que] la empresa decide hacer este proyecto? Según vos, ¿cuál sería el interés de la empresa en hacer un proyecto así como este?

Entrevistada: A mí me favorece esto porque yo necesito una vivienda. Pero creo que la empresa lo único que quiere es tapar el sol con un dedo”.

Consideramos que al emplear la metáfora alusiva a "tapar del sol con un dedo" se debe interpretar que los fines exceden el mero interés filantrópico. Tomando en consideración la conflictividad que, tal como fue presentada, existe en Puesto Viejo en materia de titularidad de la tierra, puede interpretarse que la estrategia de la empresa (de modo quizás no explícito) es buscar una solución paliativa a la tensión que subyace en materia de desigualdad en el acceso al suelo productivo. 


\section{Reflexiones finales}

Las políticas de RSE, como en este caso, evidencian la aplicación de una política empresaria global aplicada a nivel local con el fin de gestionar la conflictividad en cada localidad en que se asienta. La determinación de las condiciones que afectan a las comunidades es el principal foco de estas políticas, siempre y cuando el desarrollo de estas no suponga una asunción de responsabilidades extra-legales que devuelvan la atención sobre los impactos perjudiciales de la actividad empresarial.

Sin embargo, la creación de institucionalidad en favor de la aplicación de estas estrategias de inversión simbólica, referidas casi exclusivamente a las comunidades más próximas a las explotaciones, muestra que no es una estrategia publicitaria destinada a incrementar la participación económica en un mercado o a generar mayores ventas, sino destinada a incrementar el capital de reconocimiento (simbólico) en su medio más próximo. En ese sentido, la comunidad local es el stakeholder que conquistar, no a través de una estrategia para vender, sino a través de una que incremente la percepción de su voluntad de contribuir.

La discriminación de los intereses que persigue cada una de las estrategias como pertenecientes a diferentes campos resulta fundamental desde el punto de vista analítico. Tal como se puede evidenciar, existe una estrecha relación entre las estrategias propias del campo económico con las implementadas en el campo simbólico, y estas últimas son un retén fundamental para mitigar la percepción negativa de los impactos causados por la actividad netamente económica de la empresa. El rol de actor económico preeminente se refuerza a través de estas estrategias simbólicas reinvirtiendo rendimientos económicos en triunfos simbólicos. Por ello, la diferencia entre las dimensiones económicas y legales, por un lado, y las éticas y filantrópicas, por otro, no reside en la obligatoriedad de un grupo u otro, sino en la capacidad de una empresa de explotar el cumplimiento de ambos tipos de obligaciones (las legalmente impuestas y las voluntariamente asumidas) en favor de la finalidad de efectuar, sobre todo a nivel local, un seguro ejercicio de la dominación frente a los demás actores, entre los que se destacan las comunidades y los gobiernos locales.

La aplicación de este tipo de estrategias en el campo simbólico encuentra terreno fértil allí donde la disparidad entre los recursos simbólicos de la empresa y los destinatarios de las políticas de RSE es mayor. En comunidades rurales con grandes carencias, como la de referencia, los recursos simbólicos de los integrantes de la comunidad y su gobierno local no 
pueden lograr apalancar los recursos necesarios para revertir problemáticas tan costosas como la del hacinamiento de hogar, tal como demostraron las iniciativas que tuvieron lugar en la localidad en los últimos años, a pesar de la innegable magnitud del déficit habitacional y la recurrente movilización en favor de la reasignación de los usos del suelo adyacente a la trama urbana, así como de la función social de la propiedad privada. Por ello, en el mismo acto de ceder tierra y financiar la construcción de treinta viviendas reside la intención de seguir detentando la posición de actor local dominante.

\section{Bibliografía}

BOURDIEU, Pierre (1988) Cosas dichas. GEDISA, Buenos Aires.

BOURDIEU, Pierre (1988) La distinción. Crítica y bases sociales del gusto. TAURUS, Madrid. BOURDIEU, Pierre (2014) Las estrategias de la reproducción social. Siglo XXI Editores, Buenos Aires.

CÁRITAS ARGENTINA (2015) La dignidad también se construye. En Huellas de Esperanza. Julio de 2015. (En línea) https://www.caritas.org.ar/Boletin_Digital/2015/2015-07/Huellas-Web.html. (Consultado: 11-02-2016).

CARROLL, Archie (1991). "The pyramid of corporate social responsibility: toward the moral management of organizational stakeholders”. En Business Horizons, July-August.

CARROLL, Archie y SHABANA, Kareen (2010) The Business Case for Corporate Social Responsibility: A Review of concepts, research and practice. En International Journalof Management Reviews, 12 (1).

COMUNIDAD RSE (7 de noviembre de 2016) Holcim inauguró el proyecto Pulso Hábitat en Jujuy (En línea) http://comunidadrse.com.ar/holcim-inauguro-el-proyecto-pulso-habitat-en-jujuy/ (Consultado: 22-05-2017).

FREEMAN, R. Edward (2004). "Ethical leadership and creating value for stakeholders". En: Robert A. Peterson y O. C. Ferrell (ed.) En: Business Ethics. M. E. Sharpe, Armonk, NY, London. FREEMAN, R. Edward y REED, David (1983). "Stockholders and Stakeholders: A New Perspective on Corporate Governance”. En California Management Review, N. ${ }^{\circ} 25$ (3).

GOBIERNO DE JUJUY (19 de julio de 2017) "Entregaron en Puesto Viejo viviendas del plan Cáritas”. (En línea) http://prensa.jujuy.gob.ar/2017/07/19/se-entregaron-en-puesto-viejo-viviendas-correspondientes-al-plan-caritas/ (Consultado: 20-07-2017).

GONZÁLEZ ESTEBAN, Elsa (2007). "La teoría de los stakeholders: un puente para el desarrollo práctico de la ética empresarial y de la responsabilidad social corporativa”. En VERITAS, Revista de Filosofía y Teología, N.o 2 (17), Valparaíso. 
GUTIÉRREZ, Alicia (2011). "Estrategias de reproducción social. Las microprácticas y la política social. Capital y redes sociales”. En: Valdés Paz, J. y Espina, M. (eds.) América Latina y el Caribe: La política social en el nuevo contexto - Enfoques y experiencias UNESCO, Montevideo. GUTIÉRREZ, Alicia y MANSILLA, Héctor (2015). "Clases y reproducción social: el espacio social cordobés en la primera década del siglo XXI”. En Política y Sociedad. Vol. 52, Núm. 2, Madrid.

INSTITUTO ARGENTINO DE RESPONSABILIDAD SOCIAL EMPRESARIA (IARSE) (2007) Indicadores de Responsabilidad Social Empresaria 2007/2008. Mayo de 2007, Córdoba. INSTITUTO NACIONAL DE ESTADÍSTICAS Y CENSOS (2010) Censo Nacional de Población, Hogares y Viviendas. Disponible en http://www.indec.gob.ar/(consultado: 15-09-2016).

JUJUY AL MOMENTO (20 de marzo de 2012) Puesto Viejo: pequeños productores contra Minetti. (En línea) http://www.jujuyalmomento.com/post/6047/puesto-viejo-pequenos-productores-contra-minetti (Consultado: 13-12-206). (21 de marzo de 2012) "Productores se reunieron con Cosentini”. Disponible en Web: http://www.jujuyalmomento.com/post/6068/ puesto-viejo-productores-se-reunieron-con-cosentini (Consultado: 03/12/2016).

KURUCZ, Elizabeth, COLBERT, Barry y WHEELER, David (2008). "The business case for corporate social responsibility”. En: Crane, A., McWilliams, A., Matten, D., Moon, J. y Siegel, D. (ed.), The Oxford Handbook of Corporate Social Responsibility. Oxford: Oxford University Press.

MCGUIRE, Joseph (1963) Business and Society. McGraw-Hill, New York.

MINISTERIO DE INFRAESTRUCTURA, SERVICIOS PÚBLICOS, TIERRA Y VIVIENDA DE JUJUY, SECRETARIA DE ORDENAMIENTO TERRITORIAL Y VIVIENDA (2016) Guía para adjudicación de soluciones habitacionales. Noviembre. (En línea) http://secotyv.jujuy.gov.ar/ sorteos/informacion.html. (Consultado: 22-02-2017). (2017) Sorteo de lotes en Puesto Viejo (En línea) http://secotyv.jujuy.gov.ar/noticias/94-noticia-20170831.html (Consultado: 01-092017).

PARTIDO COMUNISTA REVOLUCIONARIO (marzo de 2012) Situación de tierras de la empresa de cementera ex Minetti. (En línea) http://www.pcr.org.ar/nota/lucha-popular/puesto-viejo-provincia-de-jujuy. (Consultado: 22-03-2016).

PÍREZ, Pedro (1995). "Actores sociales y gestión de la ciudad". En Ciudades N. ${ }^{\circ} 28$, RNIU, México, octubre-diciembre.

SANTANDREU, Alain y GUDYNAS, Eduardo (1998) Ciudadanía en movimiento. Participación ciudadana y conflictos ambientales. CLAES, FESUR y Ediciones Trilce, Montevideo.

SPECTOR, Bert (2008). "Business responsibilities in a divided world: the cold war roots of the corporate social responsibility movement”. En Enterprise \& Society, N. ${ }^{\circ} 9$. 
Artículos Arbitrados 